\title{
Effects of the use of assisted reproduction and high-caloric diet consumption on body weight and cardiovascular health of juvenile mouse offspring
}

\author{
Angela L Schenewerk, Francisco Í Ramírez ${ }^{1,3}$, Christopher Foote ${ }^{1}$, Tieming $\mathrm{Ji}^{2}$, \\ Luis A Martínez-Lemus ${ }^{1,3,4}$ and Rocío Melissa Rivera \\ Division of Animal Sciences, 164 Animal Science Research Center, University of Missouri, 920 East Campus Drive, \\ Columbia, Missouri 65211, USA, ${ }^{1}$ Dalton Cardiovascular Research Center, University of Missouri, \\ 134 Research Park Drive, Columbia, Missouri 65211, USA, Departments of ${ }^{2}$ Statistics, ${ }^{3}$ Biological Engineering \\ and ${ }^{4}$ Medical Pharmacology and Physiology, University of Missouri, Columbia, Missouri 65211, USA
}

Correspondence should be addressed to R M Rivera; Email: riverarm@missouri.edu or to L A Martínez-Lemus; Email: martinezlemusl@missouri.edu

\begin{abstract}
Maternal obesity and the use of assisted reproductive technologies (ART) are two suboptimal developmental environments that can lead to offspring obesity and cardiovascular disease. We hypothesized that these environments independently and synergistically adversely affect the offspring's weight and cardiovascular performance at $\sim 7$ weeks of age. Mice were fed either $24 \%$ fat and $17.5 \%$ high-fructose (HF) corn syrup or maintenance chow ( $5 \%$ fat; low-fat, no-fructose (LF)). Dams were subdivided into no ART and ART groups.

ART embryos were cultured in Whitten's medium and transferred into pseudopregnant recipients consuming the same diet as the donor. Offspring were fed the same diet as the mother. Body weights (BW) were measured weekly and mean arterial pressure (MAP) was collected through carotid artery catheterization at killing ( $55 \pm 0.5$ days old). Expression of genes involved in cardiovascular remodeling was measured in thoracic aorta using qRT-PCR, and levels of reactive oxygen species (ROS) were measured intracellularly and extracellularly in mesenteric resistance arteries. ART resulted in increased BW at weaning. This effect decreased over time and diet was the predominant determinant of BW by killing. Males had greater MAP than females $(P=0.002)$ and HF consumption was associated with greater MAP regardless of sex $(P<0.05)$. Gene expression was affected by sex $(P<0.05)$ and $\operatorname{diet}(P<0.1)$. Lastly, the use of $A R T$ resulted in offspring with increased intracellular ROS $(P=0.05)$. In summary, exposure to an obesogenic diet pre- and/or post-natally affects weight, MAP, and gene expression while ART increases oxidative stress in mesenteric resistance arteries of juvenile offspring, no synergistic effects were observed.

Reproduction (2014) 147 111-123
\end{abstract}

\section{Introduction}

Developmental priming and fetal programming have emerged as important hypotheses that partly explain the surge in obesity and cardiovascular disease (CVD) currently observed worldwide (WHO 2013a, 2013b). These hypotheses, collectively known as developmental origins of adult disease, assert that the uterine environment has profound effects on the body composition and cardiovascular performance of the offspring in later life (Hales \& Barker 1992, Lawlor et al. 2004).

Recent research has shown that maternal obesity, over-nutrition, and diabetes increase the incidence of glucose intolerance, arterial endothelial dysfunction, arterial stiffness, hypertension, and CVD in the offspring in humans and mice (Wildman et al. 2003, Samuelsson et al. 2008, 2010, Kelsall et al. 2012, Torrens et al. 2012,
Magliano et al. 2013). In mice, maternal obesity can result in progenies with increased body weight (BW; Samuelsson et al. 2008, Franco et al. 2012, Magliano et al. 2013). Further, Torrens et al. (2012) showed that offspring exposed to maternal obesity had decreased production of the vasodilator nitric oxide (NO), a blunted vasodilatory response to acetylcholine in the femoral artery, as well as increased systolic blood pressure at 30 weeks of age. Maternal high-caloric intake in mice has also been linked to impaired vascular responses and increased blood pressure of the offspring during adulthood (Samuelsson et al. 2008).

The use of assisted reproductive technologies (ART) has been associated with adverse outcomes in children (Olson et al. 2005, Kallen et al. 2010, Wen et al. 2010). Studies have shown that the use of IVF results in an 
increased risk for congenital malformations such as cardiac septal defects, neural tube defects, and cleft palate (Olson et al. 2005, Reefhuis et al. 2009, Kallen et al. 2010). In addition, Wen et al. (2010) found that the risk for congenital heart defects with the use of ART was amplified when the mother was obese.

Retrospective studies in humans (Wikstrand et al. 2008, Ceelen et al. 2009, Sakka et al. 2010) have also pointed at the method of conception as a causative factor for abnormal cardiovascular parameters in children during postnatal development. For example, it has been demonstrated that children conceived by the use of ART have increased systolic and diastolic blood pressure, increased vascular dysfunction, and decreased retinal vascular branching (Ceelen et al. 2008, Wikstrand et al. 2008, Sakka et al. 2010, Scherrer et al. 2012). Similarly, in mice, an association exists between ART and an elevated systolic blood pressure (Watkins et al. 2007). Further, increased angiotensin converting enzyme, which cleaves angiotensin I into the vasoconstrictor angiotensin II, has also been observed in mice offspring conceived via ART (Watkins et al. 2007). Lastly, the use of ART has been associated with increased adiposity in children (Ceelen et al. 2007, Belva et al. 2012). For example, children conceived by IVF and ICSI have higher levels of peripheral adiposity than agematched naturally conceived controls at 8-18 years of age (Ceelen et al. 2007, Belva et al. 2012).

CVD is the number one cause of death. In 2008, CVD accounted for $30 \%$ of deaths worldwide (WHO 2013b). Obesity and hypertension are two important contributors to the high incidences of CVD mortality worldwide (WHO 2013b). The development of hypertension has been proposed to involve the matrix metalloproteinases (MMPs) and reactive oxygen species (ROS) (MartínezLemus \& Galinanes 2011). ROS can mediate the expression and activation of MMPs (Siwik et al. 2001, Martínez-Lemus et al. 2011, Zhang et al. 2013). In the vasculature, ROS are mainly produced by the enzyme NADPH oxidase (NOX (Cai et al. 2003)). MMPs are involved in processes such as the degradation of the extracellular matrix (ECM), the cleavage of extracellular receptors (Rodrigues et al. 2010), disruption of cellular adhesions (Yang et al. 2007), and shedding of vasoactive factors within the ECM (Hao et al. 2004). Specifically, MMP2 and MMP9 have been implicated in vascular remodeling, and MMP7 might also be involved as it appears to play a role in hypertension (Lehoux et al. 2004, Wang et al. 2009, Martínez-Lemus et al. 2011). Tissue inhibitors of MMPs (TIMPs) are endogenous inhibitors of the MMPs, and an imbalance between TIMPs and MMPs has been implicated in pathological conditions (Gomez et al. 1997).

Maternal obesity and the use of ART often coincide because many women of reproductive age face infertility, and the number of them who attend ART clinics is rising (Robker 2008). It is clear that obesity and ART are each predisposing children to CVD. However, given the short history of the use of ART, no studies have yet addressed the threat of CVD from the combination of the two suboptimal maternal environments, despite the large number of children who have been exposed to it. In the current study, we hypothesize that obesity and ART independently and synergistically adversely affect the cardiovascular health and BW of the offspring. We further hypothesize that these two suboptimal developmental environments are associated with higher blood pressure in the offspring and that this is associated with expression of the MMPs, TIMPs, and NOXs in the vasculature. To test these hypotheses, two suboptimal developmental environments were used; namely, those that exist with an obesogenic environment and with the use of ART. We sought to determine what effect these two environments, either alone or in combination, would have on cardiovascular health markers in juvenile mice offspring ( $\sim 7$ weeks of age). The measures of cardiovascular health chosen in this study were mean arterial pressure (MAP), the expression of genes implicated in poor cardiovascular health and vascular remodeling (Mmp2, Mmp9, Timp1, and Cybb (Nox2)), and levels of intracellular and extracellular ROS. We also measured offspring BW weekly up to their killing, as high BW has been associated with adverse cardiovascular outcomes (NIH 2012).

\section{Materials and methods}

\section{Animals}

All animal procedures were approved by the Institutional Animal Care and Use Committee of the University of Missouri under protocol number 7501. The strain of the females used for this experiment was NSA (CF1; Harlan Laboratories, Indianapolis, IN, USA) while the strain of the studs and vasectomized males was B6D2F1/J (The Jackson Laboratory, Bar Harbor, ME, USA). Females were between 6 and 10 weeks of age and were housed under $12 \mathrm{~h}$ light: $12 \mathrm{~h}$ darkness cycle between 20 and $23.3{ }^{\circ} \mathrm{C}$ in groups until conception when they were individually caged. Mice were given access to water and the appropriate diet and allowed to feed ad libitum.

\section{Diet}

Experimental animals were fed either a 'high-fat, high-fructose' (HF) or a 'low-fat, no-fructose' (LF) diet. The HF group were fed a diet containing $24 \%$ fat and $17.5 \%$ HF corn syrup from TestDiet 58Y1 (TestDiet, St Louis, MO, USA) ad libitum. The calories (kcal\%) provided by the HF diet are as follows: protein, $17.6 \%$; carbohydrate, $36 \%$; and fat, $46.4 \%$. The females in the LF group were fed a diet containing $5 \%$ fat (measured by ether extraction; Lab Diets 5001, PMI Nutritional International, St Louis, MO, USA) ad libitum. The calories (kcal\%) provided by the LF diet is as follows: protein, $28.5 \%$; carbohydrate, $58 \%$; and fat, $13.5 \%$. The LF females were given Lab Diet 5008 $(6.5 \%$ fat) during pregnancy and lactation. The calories (kcal\%) 
provided by the LF pregnancy diet are as follows: protein, $26.8 \%$; carbohydrate, $56.4 \%$; and fat, $16.7 \%$. The HF diet administered prior to and during pregnancy and lactation was TestDiet $58 Y 1$ ( $46 \% \mathrm{kcal}$ fat with corn syrup). Note: the terms 'maternal and offspring consumption of HF diet' and 'exposure to an obesogenic diet' will be used interchangeably.

\section{Control (no ART) groups}

The control females were fed the HF or LF diet at least 3 weeks prior to being paired with proven fertility B6D2F1/J males. Three weeks were chosen because this is the approximate time required for oocyte development in mice (Eppig et al. 2002). Copulation was confirmed by visual observation of a copulatory plug. Pregnant females were placed in a separate cage and were allowed to carry the pregnancy to term. Twelve total control females were paired with fertile males (six HF and six LF), but one HF female did not become pregnant. After birth, the litters were culled to eight pups (four males and four females, when possible), to help control for the smaller litter sizes in the ART groups.

\section{Assisted reproduction groups}

Three ART procedures were used in this experiment, namely superovulation, embryo collection and culture, and embryo transfer in order to simulate three procedures commonly used in human ART.

\section{Superovulation}

Females of 6-10 weeks of age fed either HF or LF diet for 3 weeks before superovulation received an i.p. injection of 5 IU equine chorionic gonadotropin (Calbiochem, La Jolla, CA, USA) followed by 5 IU human chorionic gonadotropin (hCG; Sigma) $45 \mathrm{~h}$ later. The injections were given to increase the number of oocytes ovulated by each animal. Superovulated females were then co-caged overnight with B6D2F1/J intact males.

\section{Embryo collection and culture}

Two-cell embryos were harvested from the oviduct $\sim 46 \mathrm{~h}$ post-hCG injection. Oviducts were flushed with warm bicarbonate-free minimal essential medium (Earle's salt) supplemented with $3 \mathrm{mg} / \mathrm{ml}$ polyvinylpyrrolidone (PVP) and $25 \mathrm{mM}$ HEPES (MEM+PVP ( $\mathrm{pH} 7.3$ ); Sigma). Embryos were washed from debris with three consecutive washes in MEM+ PVP and once in Whitten's medium. Whitten's medium was prepared as previously published by us (Negron-Perez et al. 2013). Whitten's medium has previously been shown to support development to term (Ecker et al. 2004, Sommovilla et al. 2005), although it is known to be a suboptimal culture medium (Rinaudo \& Schultz 2004). We purposely used this medium to determine whether the cardiovascular measures examined in the current study would be adversely affected by a suboptimal culture medium, as such findings could direct the focus of future studies in more favorable culture media. The embryos were cultured at $37^{\circ} \mathrm{C}$ in Whitten's medium in an atmosphere of $5 \% \mathrm{CO}_{2}$ in air at a density of one embryo per $\sim 3.5 \mu \mathrm{l}$ of medium. Embryos were cultured for 3 days (or 116-h post-hCG) at which time zona-enclosed blastocysts were transferred to the uteri of day 2.5 (d2.5) pseudopregnant NSA (CF1) females.

\section{Embryo transfers}

Females designated as embryo recipients (NSA (CF1)) were fed HF or LF diets at the same time as the embryo donors prior to receiving the superovulation protocol described above. Immediately after the hCG injection, the females were co-caged overnight with vasectomized B6D2F1/J males. Females that showed a copulatory plug the following morning (denoted as d0.5 of pseudopregnancy) were selected as potential embryo recipients. A plane of anesthesia was reached by an i.p. injection of the $2.5 \%(\mathrm{w} / \mathrm{v})$ Avertin stock at $0.014 \mathrm{ml} / \mathrm{g} \mathrm{BW}$ (Nagy et al. 2003). Twenty blastocyst-stage embryos produced as described above were transferred (ten/uterine horn) to embryo recipients on $\mathrm{d} 2.5$ of pseudopregnancy according to standard procedures (Nagy et al. 2003). Pseudopregnant recipients were consuming the same diet as the embryo donor. Pregnant recipients were returned to their cages and allowed to carry their pregnancies to term. Forty-five transfers were performed (22 LF and $23 \mathrm{HF}$ ). Nearly $27 \%$ of transfers resulted in pregnancy (determined by birth of offspring; Supplementary Table 1, see section on supplementary data given at the end of this article).

\section{Pregnancy, lactation, and weaning}

All females were maintained on the diet they had been consuming prior to becoming pregnant until their role in the experiment was completed at weaning. Offspring were weaned from the mothers at 22 days postpartum. They were separated by sex and placed on the same diet that the mothers had consumed until killed.

\section{Measurement of offspring $B W$}

BW was recorded using a standard scale (Mettler Toledo, Columbus, OH, USA) 5 days after birth, and every week thereafter until kill. Control litters were culled to eight (four males and four females, when possible) at the 5-day weighing to control for the larger litter sizes in the control groups. No identification marks were used prior to weaning; therefore, weights were recorded separately for males and females from each litter and averaged each week during the first 3 weeks. Each individual received an identifying ear punch at weaning, and weights were recorded by an individual from that point onward.

\section{MAP measurement}

Offspring male $(n=37)$ and female $(n=31)$ mice $55.5 \pm 0.5$ $(n=68)$ days old were anesthetized by inhalation of $5 \%$ isoflurane until visible loss of consciousness. At that point, mice were placed in dorsal recumbency and maintained under anesthesia at $3 \%(\mathrm{v} / \mathrm{v})$ through a cone covering the nose and mouth until surgical plane anesthesia was confirmed by loss of 
spinal reflexes. The right carotid artery was cannulated with a polyethylene catheter (PE-10) filled with phosphate-buffered physiological saline solution (PSS) containing $100 \mathrm{U} / \mathrm{ml}$ heparin. The catheter was connected to a pressure transducer in order to measure MAP with the use of a PowerLab 4/30 Data Acquisition System (ADInstruments, Colorado Springs, CO, USA). Following catheterization, the level of anesthesia was lowered to $2 \%(\mathrm{v} / \mathrm{v})$ for $10 \mathrm{~min}$, and the average systolic and diastolic pressures recorded during the final minute were used to calculate MAP. It should be noted that three animals had bleeding during catheterization and were excluded from the MAP analysis as blood loss can affect pressure.

\section{Mesenteric resistance artery and thoracic aorta collection}

Subsequent to MAP measurement, animals were killed under anesthesia. A portion of the mesentery was excised and pinned flat in a refrigerated $\left(4^{\circ} \mathrm{C}\right)$ dissecting chamber containing PSS of the following composition (in mmol/l): $145.0 \mathrm{NaCl}, 4.7 \mathrm{KCl}$, $2.0 \mathrm{CaCl}_{2}, 1.2 \mathrm{MgSO}_{4}, 1.0 \mathrm{NaH}_{2} \mathrm{PO}_{4}, 5.0$ dextrose, $3.03-$ (N-morpholino) propanesulfonic acid buffer, 2.0 pyruvate, 0.02 EDTA, and 0.15 BSA, pH 7.4. Small pieces ( $3 \mathrm{~mm}$ length) of second-order mesenteric resistance arteries were isolated and stored at $-70{ }^{\circ} \mathrm{C}$ for subsequent analysis of ROS using HPLC. A small section ( $\sim 5 \mathrm{~mm}$ length) of the thoracic aorta was also collected and stored at $-70^{\circ} \mathrm{C}$ for quantitative RT-PCR analysis. Owing to time constraints for the processes performed, tissues were only collected for two animals per day. In order to keep the age average similar between the ART and no ART groups, 34 of the 36 ART offspring and 34 of the 87 no ART controls were collected and used for the remainder of the study. The collected offspring were selected to have at least one male and one female for each mother. Two or three offspring were collected from all the control females except for the last LF control female (three males and three females were collected) and the last two HF control females (two males and two females were collected). All ART-conceived pups were collected except for two HF males who had advanced too far in age by the time of collection.

\section{Dihydroethidium incubation of single mesenteric resistance arteries for detection of ROS}

Isolated pieces of mesenteric resistance arteries were taken from the $-70{ }^{\circ} \mathrm{C}$ freezer, placed in $99 \mu \mathrm{l} 1 \times \mathrm{PBS}(137 \mathrm{mM}$ $\mathrm{NaCl}, 2.7 \mathrm{mM} \mathrm{KCl}, 10 \mathrm{mM} \mathrm{Na} \mathrm{HPO}_{4}$, and $1.8 \mathrm{mM} \mathrm{KH}_{2} \mathrm{PO}_{4}$ ) with $100 \mu \mathrm{M}$ diethylene triamine pentaacetic acid (DTPA) (Sigma-Aldrich), and incubated in a $37^{\circ} \mathrm{C}$ water bath for $10 \mathrm{~min}$. The $100 \mu \mathrm{M}$ DTPA was prepared as described previously (Buettner 2008). Briefly, $0.1967 \mathrm{~g}$ DTPA was added to $1.7 \mathrm{ml} 1 \mathrm{M} \mathrm{NaOH}$ to make the DTPA go into solution more easily. The flask was then filled to $\sim 40 \mathrm{ml}$ with ultrapure $\mathrm{H}_{2} \mathrm{O}$. The solution was sonicated to bring the DTPA into solution. Then, the solution was adjusted to a $\mathrm{pH}$ of 7.1 using a $1 \mathrm{M} \mathrm{HCl}$ solution before bringing the solution to a final volume of $50 \mathrm{ml}$ with ultrapure $\mathrm{H}_{2} \mathrm{O}$. A $5 \mathrm{mM}$ stock solution of dihydroethidium (DHE) was made by dissolving $1 \mathrm{mg}$ DHE (Molecular Probes-Life Technologies) in $634 \mu \mathrm{l}$ DMSO
(Sigma). The resulting solution was separated into $15 \mu \mathrm{l}$ aliquots and lyophilized for $2 \mathrm{~h}$. The lyophilized DHE aliquots were stored at $-20{ }^{\circ} \mathrm{C}$ until use. On each day of the experiment, the lyophilized DHE was resuspended in $15 \mu \mathrm{l}$ pure HPLC-grade acetonitrile. After the initial incubation, $1 \mu \mathrm{l}$ of a $5 \mathrm{mM}$ DHE stock in acetonitrile was added to the solution bathing the vessel to bring the final concentration to $50 \mu \mathrm{M}$ DHE. Ambient light was avoided to diminish excess oxidation of the DHE. The resistance artery was incubated with DHE at $37^{\circ} \mathrm{C}$ in the water bath for $1 \mathrm{~h}$, with gentle agitation every $10 \mathrm{~min}$. The vessel was then removed and washed twice, consecutively, in $400 \mu \mathrm{l} 1 \times$ PBS.

\section{Fluorescence confocal microscopy for detection of intracellular ROS}

After being washed in $1 \times$ PBS, the vessels were placed on a glass slide in a drop of $1 \times$ PBS and covered with a 1.5 thickness coverslip. Two random areas were chosen to be imaged for each vessel. Images were obtained using a Leica True Confocal Scanning-Spectral Photometric 5 DMI 6000 Confocal Laser Scanning Microscope (Leica TCS SP5). A 3D image was obtained for each section at a photomultiplier gain of $800 \mathrm{~V}$ using a $20 \times$ dry lens. DHE was detected using a multi-photon excitation of $800 \mathrm{~nm}$ and an emission detection in the range of 600-700 nm. DHE has previously been used to detect superoxide in arterioles (Martínez-Lemus et al. 2011), as it forms a red fluorescent product upon oxidation (Owusu-Ansah et al. 2008). Laser scanning was performed using a resonator set at $8000 \mathrm{~Hz}$ to reduce photo bleaching. Z-sections were set at $0.5 \mu \mathrm{M}$ to cover the entire vessel. All images were taken at the same excitation power and detection parameters. Analysis of relative DHE fluorescence was performed using Imaris 7.6.1 Software (South Windsor, CT, USA) over an area of $150 \times 150 \times$ 20 pixels for each vessel. Values for DHE fluorescence were averaged over the two areas of the vessel that were imaged. Readings for intracellular ROS were excluded if there was discrepancy in the relative DHE fluorescence between the two areas on the vessel from the same individual.

\section{HPLC}

HPLC was performed using $50 \mu$ of the original DTPA $+1 \times$ $\mathrm{PBS}+\mathrm{DHE}$ solution used to bathe the resistance artery in order to detect the oxidation of DHE outside the cells, which is a measure of extracellular ROS production. A C8 reverse-phase column (Phenomenex, Torrance, CA, USA) was used to separate the two byproducts of DHE oxidation, 2-hydroxyethidium (2-OH-Et), and ethidium (Et). The phase solutions used for product separation were Solution A (ultrapure water), Solution B $(99.9 \% \mathrm{v} / \mathrm{v}$ water with $0.1 \% \mathrm{v} / \mathrm{v}$ trifluoroacetic acid (TFA)), and Solution C (99.9\% v/v acetonitrile with $0.1 \%$ v/v TFA; Fischer, Pittsburgh, PA, USA). The samples were placed in a Waters 2590 Separation Module and 2-OH-Et and Et fluorescence were detected using a Waters 474 Scanning Fluorescence detector set at an excitation of $510 \mathrm{~nm}$ and emission of $595 \mathrm{~nm}$. Each day before running samples, the column was cleaned by running $99.9 \% \mathrm{v} / \mathrm{v}$ acetonitrile with $0.1 \% \mathrm{v} / \mathrm{v}$ TFA for $20 \mathrm{~min}$ at a flow of $1 \mathrm{ml} / \mathrm{min}$, 
followed by $100 \%$ ultrapure water at a flow of $0.5 \mathrm{ml} / \mathrm{min}$ for $20 \mathrm{~min}$. This cleaning was repeated after every four or five samples to stop the pressure in the column from increasing. For each sample being run, a gradient of acetonitrile $(\mathrm{v} / \mathrm{v})$ in water was used to elute the samples. The gradient was run at a flow of $0.4 \mathrm{ml} / \mathrm{min}$ with an increase in acetonitrile from 10 to $46 \%$ in the first $10 \mathrm{~min}$, an increase again to $100 \%$ from 20 to $25 \mathrm{~min}$, and ending with the original $10 \%$ acetonitrile from 25 to $35 \mathrm{~min}$ to clean the column. The 2-OH-Et eluted at 16.19 $\pm 0.03 \mathrm{~min}$ and the Et eluted at $16.61 \pm 0.03 \mathrm{~min}$. The Empower program (Waters, Milford, MA, USA; Build \#1154) was used to extract the areas under the 2-OH-Et and Et peaks detected by the fluorescence detector. One vessel for a LF no ART control male was lost during transfer to the DHE incubation step, so this observation is not included.

\section{Homogenizing vessels for protein measurement}

An Omni Bead Ruptor 24 Homogenizer (Omni International, Kennesaw, GA, USA) was used to pulverize the resistance arterioles. After the confocal image was taken, the vessels were placed in a $0.5 \mathrm{ml}$ tube with a cap (Omni International) with $100 \mu \mathrm{l}$ pure HPLC-grade acetonitrile and $50 \mathrm{mg} 0.1 \mathrm{~mm}$ glass beads (Omni International). The program for homogenization was performed at $22{ }^{\circ} \mathrm{C}$. There were three cycles, each at a speed of $8 \mathrm{~m} / \mathrm{s}$ for $45 \mathrm{~s}$, with a $3 \mathrm{~s}$ wait time between cycles. The tubes were centrifuged briefly after homogenization to ensure the beads were at the bottom of the tube, and $60 \mu \mathrm{l}$ of the supernatant was recovered. This supernatant was sonicated for 1 min to further lyse the tissue. Then, the solution was centrifuged at $2000 \mathrm{~g}$ for $10 \mathrm{~min}$, and $50 \mu \mathrm{l}$ of the supernatant was removed. The remaining $10 \mu \mathrm{l}$ was used for protein measurement using a Micro BCA Kit.

\section{Protein assays using MicroBCA kit}

Each sample was diluted 1:4 (v/v) in pure HPLC-grade acetonitrile (Fischer) prior to protein detection. The Micro BCA Protein Assay Kit (Pierce, Rockford, IL, USA) was used to detect the concentration of protein for each sample. A standard curve with BSA was generated using a blank (pure acetonitrile) and the concentrations from 1 to $200 \mu \mathrm{g} / \mathrm{ml}$ in acetonitrile. The working reagent was prepared in accordance with manufacturer's instructions. Reactions were prepared by mixing $4 \mu \mathrm{l}$ of the BSA standard or diluted sample with $4 \mu$ of the working reagent. The reactions were incubated at $60{ }^{\circ} \mathrm{C}$ for $1 \mathrm{~h}$ and then allowed to cool to room temperature. A Nanodrop Spectrophotometer was used to measure the absorbance of each sample at $562 \mathrm{~nm}$. A standard BSA curve was performed each day, and the sample absorbances were plotted against the standard curve to determine the concentration $(\mu \mathrm{g} / \mathrm{ml})$.

\section{RNA extraction from thoracic aorta and RT-PCR}

RNA isolation was performed on thoracic aorta segments using the DynaBEADS mRNA Direct Kit (Invitrogen). The Dynabead Oligo (dT) 25 beads were equilibrated according to the manufacturer's instructions. For RNA and DNA isolation, thoracic aorta segments were placed in $200 \mu \mathrm{l}$ lysis buffer (100 mM Tris-HCl, $500 \mathrm{mM} \mathrm{LiCl,} 10 \mathrm{mM}$ EDTA, 1\% LiDS, and $5 \mathrm{mM}$ dithiothreitol (DTT)), pulverized with a DNase-RNasefree pestel, and then sheared by passing through a 20 gauge needle followed by a 22 gauge needle. Isolation of mRNA separated from the beads was then performed following manufacturer's specifications. The final wash of the beads was performed in $20 \mu \mathrm{l}$ sterile water and then heated at $80{ }^{\circ} \mathrm{C}$ for 2 min to separate the mRNA from the beads. The water with the mRNA was quickly removed from the beads, and $3 \mu \mathrm{l}$ was used for the creation of a $60 \mu \mathrm{l}$ cDNA reaction using $100 \mathrm{U}$ Superscript II Reverse Transcriptase (Invitrogen) and the following $(1 \times$ First-Strand Buffer, $10 \mathrm{mM}$ DTT, $0.8 \mathrm{mM}$ dNTPs, $0.5 \mu \mathrm{g}$ random primers, and $44 \mathrm{U}$ RNasin). The reaction was incubated at $42{ }^{\circ} \mathrm{C}$ for $1 \mathrm{~h}$ followed by $95{ }^{\circ} \mathrm{C}$ for $10 \mathrm{~min}$. One microliter of the resulting cDNA was used for each qRT-PCR. Procedures were followed using manufacturer's instructions; thus, a template quantification step was not used.

\section{Quantitative real-time PCR for gene expression in thoracic aorta}

The TaqMan Gene Expression Assays (Applied Biosystems, Life Technologies) used are shown (Table 1). No DNase treatment was performed as cDNA preparation was performed as per the manufacturer's instructions. However, as an extra precaution and to ensure no DNA amplification, all TaqMan probes used were intron spanning. After RT, cDNA $(1 \mu \mathrm{l})$ underwent realtime PCR amplification with $10 \mu \mathrm{l} 2 \times$ TaqProbe qPCR Mastermix-low ROX (BEQPCR-PL; MidSci, St Louis, MO, USA), $8 \mu$ l sterile water, $1 \mu \mathrm{l} 20 \times$ TaqMan Gene Expression Assays probe ((Life Technologies); see Table 1 for probe information). The reactions were performed in triplicate using a 7500 Real-Time PCR Machine (Applied Biosystems) with the following cycles: $50{ }^{\circ} \mathrm{C}-2 \mathrm{~min} ; 95^{\circ} \mathrm{C}-1 \mathrm{~min} ; 40$ cycles of $95^{\circ} \mathrm{C}-15 \mathrm{~s}$; and $60{ }^{\circ} \mathrm{C}-1 \mathrm{~min}$. Genes analyzed were Mmp2 (Mm00439498_m1), Mmp7 (Mm00487724_m1), Mmp9 (Mm00442991_m1), Timp1 (Mm00441818_m1), and Cybb

Table 1 TaqMan probes used for quantitative RT-PCR analyses in mouse thoracic aorta.

\begin{tabular}{ll}
\hline Names (NCBI accession no.) & Sequences \\
\hline B2m (NM_009735.3) & CGGCCTGTATGCTATCCAGAAAACC \\
Mmp2 (NM_008610.2) & ACCAGATCACATACAGGATCATTGG \\
Mmp7 (NM_010810.4) & GGAACAGGCTCAGAATTATCTTAGA \\
Mmp9 (NM_013599.2) & TCCAGTACCAAGACAAAGCCTATTT \\
Timp1 (NM_001044384.1 and NM_011593.2) & CTGCAACTCGGACCTGGTCATAAGG \\
Cybb (NM_007807.4) & AGTGAACACCCTAACACCACAATAG \\
\hline
\end{tabular}

$\mathrm{NCBI}$, National Center for Biotechnology Information. No.=number. Bp= base pairs. 
(Nox2; Mm01287743_m1). The average threshold cycles $\left(C_{\mathrm{T}}\right)$ for the cDNA were normalized to the expression level of $\beta-2$ microglobulin (B2m; Mm00437762_m1). B2m is a gene involved in immune response as a member of the major histocompatability complex class 1 and is not involved in energy metabolism (Shertzer et al. 2013). B2m has been previously shown to be stable in high-fat diet-induced oxidative stress in adipose tissue (Bailey-Downs et al. 2013), and in response to oxidative stress in the brain (Shertzer et al. 2013) and lung (Shimada et al. 2009). A $C_{\mathrm{T}}$ above 35 was considered to be not expressed, and measurements with S.D. above 0.5 were discarded and repeated. Two LF male ART offspring were unable to be analyzed for gene expression due to complications during mRNA isolation. Five or six no ART controls were selected randomly from each group (HF males, LF males, HF females, and LF females) to be used for gene expression analysis.

\section{Statistical analysis}

The logarithms of offspring BW were regressed on the ART effect (pregnancy through ART or not), diet effect (HF or LF), sex effect (female or male), and time effect (weaning, fourth week, fifth week, sixth week, and seventh week since birth), as well as interaction effects including sex by diet, ART by time, and diet by time. Mothers were included as random effects in the model to capture the correlations between offspring that have the same mother. As repeated measurements for the same offspring were taken at all time points, compound symmetry correlation structure was used to model the correlations among these observations. The model was constructed and chosen by biological considerations and diagnostic statistics. The main effects and interaction effects were statistically significant at level 0.05 . The compound symmetry correlation structure for modeling the repeated measurements on the same offspring was chosen for its highest likelihood and lowest Akaike information criterion, Bayesian information criterion statistics. The studentized residual plot and normal quantile-quantile plot suggest a consistent normality assumption and do not indicate any obvious outliers. At the time of killing, correlations were computed and tested between the logarithms of BW, intracellular ROS, extracellular ROS (2-OH-Et and Et), and the differences in cycle thresholds of Mmp2, Mmp9, Timp1, and $C y b b$.

We also examined the associations between the diet, ART, and sex effects with MAP and gene expression. The significance of each of the three effects (diet, ART, and sex) was tested within fixed levels of the other two. For example, the association between diet and MAP (or gene expression) was tested within fixed levels of ART and sex.

\section{Results}

\section{Effects of ART and diet on BW from weaning to killing}

Increased offspring BW has been observed separately in models of maternal obesity and ART (Ceelen et al. 2007, Samuelsson et al. 2008, Nelson et al. 2010, Belva et al. 2012, Morandi et al. 2012). We sought to determine whether the combination of ART and high-fat diet consumption by the mothers and offspring would amplify the increase in BW expected in the offspring. The use of ART resulted in offspring with increased BW when compared with no ART controls (no ART; $P<0.0001$ ) at weaning (i.e. 22 days of age; Fig. 1A). However, this effect diminished over time as the no ART group began to catch up in growth and resulted in nonsignificant BW differences at killing (i.e. $55 \pm 0.5$ days; $P=0.1052$ ). Additionally, maternal and offspring consumption of a HF diet resulted in increased $\mathrm{BW}$ of the offspring from weaning $(P<0.0001)$ until killing (Fig. 1B; $P<0.0001)$. Male offspring weighed significantly more than females from weaning until killing $(P<0.0001$; Fig. 1C). No effect of the interaction between diet and ART was observed in this study $(P>0.05$; data not shown). However, there was an interaction between diet and sex. Males in the HF group had a greater increase in BW when compared with the LF males at killing than the HF females did when compared with the LF females $(P<0.03 ; 34.03 \pm 0.71$ vs $28.77 \pm 0.41 \mathrm{~g}$ and $24.12 \pm 0.48$ vs $21.91 \pm 0.37$ g respectively).

\section{Effects of sex and diet on MAP}

Hypertension is another common risk factor for the development of CVD (WHO 2013b). We used MAP (1/3 systolic $+2 / 3$ diastolic pressure) as a measure of blood pressure in the offspring. Overall, males had a higher MAP than females at killing $(P=0.002 ;$ Fig. $2 \mathrm{~A})$. This increased MAP was associated with an increased $B W$ at 7 weeks of age in males when compared with females $(P<0.0001$; Fig. 1C). Further, MAP was positively correlated with BW at killing $(P<0.02$; Table 2). Diet also had an effect on offspring MAP $(P<0.05)$ after taking into account ART and sex effects. When offspring consumed a HF diet after developing in a HF maternal environment, they had higher MAP than offspring that had been exposed to a LF diet throughout (Fig. 2B). We did not observe increased blood pressure due to ART ( $P>0.05$, Supplementary Figure 1, see section on supplementary data given at the end of this article).

\section{Gene expression in response to diet and sex}

Altered activities of MMP2, MMP7, MMP9, TIMP1, and NOX-derived ROS have been associated with CVD (Gomez et al. 1997, Lehoux et al. 2004, Wang et al. 2009). Further, MMP2 and MMP9 have been suggested to be involved in ROS-dependent vascular remodeling associated with hypertension (Martínez-Lemus et al. 2011). We examined gene expressions of $\mathrm{Mmp2}$, Mmp7, Mmp9, Timp1, and Cybb in the thoracic aorta of offspring from the different treatment groups to determine whether these possible markers of cardiovascular health were affected by the two treatments 
alone or in combination. Offspring who were exposed to an obesogenic diet had lower expression of $\mathrm{Mmp9}$ and a tendency toward lower expression of Mmp2 when compared with offspring in the LF group $(P<0.05$ and $P<0.1$ respectively; Fig. $3 \mathrm{~A}$ and $\mathrm{C})$. Further, males had decreased expression of Mmp2 and the inhibitor Timp1 $(P<0.05$ and $P<0.04$ respectively; Fig. $3 \mathrm{~B}$ and $\mathrm{D})$ when compared with females. No difference in expression of $C y b b$ was observed between treatment groups $(P>0.05$;
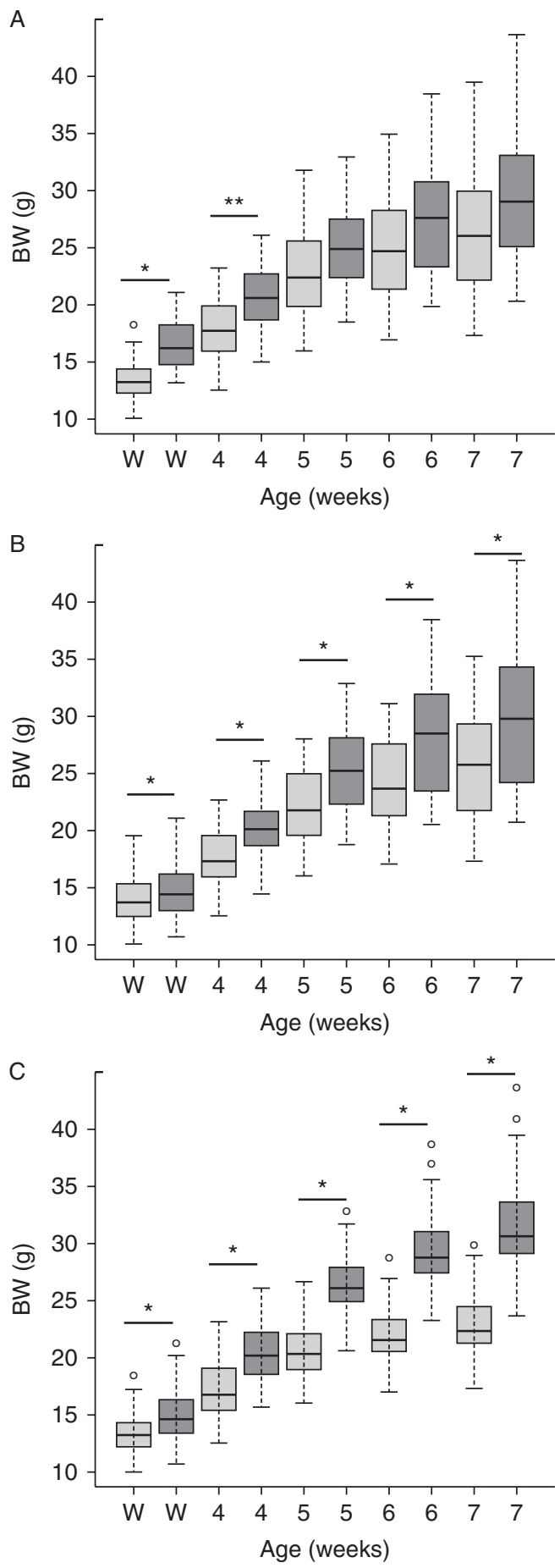

data not shown). Also, the use of ART did not show a significant difference in the expression of any of the genes assayed in this study $(P>0.05$; Supplementary Figure 2, see section on supplementary data given at the end of this article). Mmp7 expression was not detected in the thoracic aorta of the offspring from any treatment.

Several correlations with gene expression were observed in the offspring. The expression of all the genes analyzed (Mmp2, Mmp9, Timp1, and Cybb) was positively correlated with each other $(P<0.01$; Table 2$)$. The differences in cycle thresholds of $\mathrm{Mmp2}$ also had a positive correlation and Mmp9 tended to have a positive correlation with BW at killing $(P=0.02$ and $P=0.06$ respectively; Table 2 ). Therefore, as the BW increased, the expression of Mmp2 decreased and Mmp9 tended to decrease.

\section{Effect of ART on ROS in offspring mesenteric resistance arteries}

Previous research has shown increased oxidative stress, which can occur due to increased ROS, in obesity as well as with the use of ART (Chao et al. 2005, Torrens et al. 2012). We examined the levels of intracellular or extracellular ROS in mesenteric resistance arteries of the experimental offspring. Offspring produced by ART had increased intracellular ROS in mesenteric resistance arteries $(P=0.05 ; 45.2 \pm 2.47$ and 37.67 \pm 1.97 respectively; Fig. 4B, C1 and C2). There was no significant difference in intracellular ROS between the $\mathrm{HF}$ and LF groups $(P>0.05 ; 41.96 \pm 2.35$ and $40.94 \pm$ 2.27 respectively) or between the males and females $(P>0.05 ; 39.57 \pm 2.08$ and $43.64 \pm 2.57$ respectively). Further, we did not observe a significant difference in the oxidation level of DHE outside the cells, indicating that extracellular ROS did not differ in the mesenteric

\footnotetext{
Figure 1 Effects of ART, diet, and sex on mouse offspring body weight from weaning until 7 weeks of age. (A) Body weights for all offspring conceived by natural conception (no ART; $n=87$; light gray bars) or with the use of ART (ART; $n=36$; dark gray bars). (B) Body weights for all offspring conceived by from mothers consuming a maintenance chow (LF; $n=68$; light gray bars) or a diet containing $24 \%$ fat and $17.5 \%$ high-fructose corn syrup (HF; $n=55$; dark gray bars). (C) Body weights of females ( $n=60$; light gray bars) and males ( $n=63$; dark gray bars). Comparisons were made at weaning ( 22 days), week 4 (26 days), week 5 (33 days), week 6 (40 days), and week 7 (47 days). The middle bar in a box shows the median (50\%) body weight. The upper and lower borders of a box show the first and third quartiles (25 and 75\% respectively) of a group body weight. The bars above or below the dash lines mark the body weights that are 2.5 times of a quartile away from the median. Dots outside of bars are even further away from the median. ART, assisted reproductive technologies; BW, body weight. Solid black lines with asterisks above are used to demarcate statistical differences between groups at given times after birth. ${ }^{*} P<0.0001$ and $* * P<0.05$.
} 

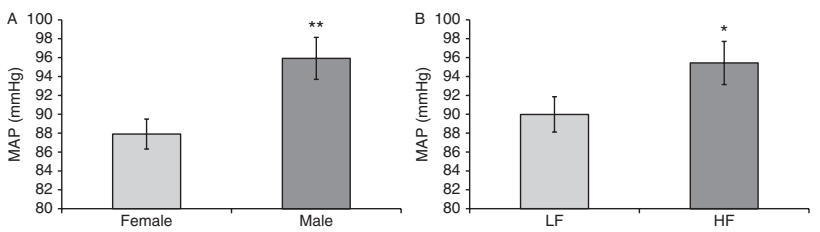

Figure 2 Mean arterial pressure (MAP) in offspring at killing. Carotid artery catheterization was performed to measure MAP as a representation of blood pressure in the offspring immediately prior to killing (55 \pm 0.5 days). (A) MAP in female $(n=29)$ and male $(n=33)$ offspring. (B) MAP in LF $(n=37)$ and HF $(n=25)$ offspring. The bars represent the mean \pm S.E.M. LF, maternal and offspring consumption of a maintenance chow; HF, maternal and offspring consumption of a diet containing $24 \%$ fat and $17.5 \%$ high-fructose corn syrup. ${ }^{*} P<0.05$ and ${ }^{* *} P<0.01$.

resistance arteries between treatment groups $(P>0.05$; data not shown).

2-OH-Et and Et as measured by HPLC in the extracellular solution containing DHE are a measure of extracellular superoxide $\left(\mathrm{O}_{2}^{-}\right)$production and nonspecific ROS production respectively. Intracellular ROS did not correlate significantly with either extracellular 2-OH-Et or Et ( $P>0.05$, data not shown). When extracellular 2-OH-Et was increased, Et was also increased $(P<0.001$; Table 2). Extracellular 2-OH-Et was negatively correlated with the differences in cycle threshold of Mmp2, Mmp9, Timp1, and Cybb $(P<0.01$, $P<0.01, P<0.01$, and $P<0.02$ respectively; Table 2 ), meaning that as the expression of each of the four genes was increased, extracellular superoxide was also increased. Extracellular Et was negatively correlated with the differences in cycle threshold of all the genes analyzed (Table 2). Also, there was a negative correlation between extracellular 2-OH-Et and MAP (Table 2).

\section{Discussion}

Both ART (Ceelen et al. 2007, Belva et al. 2012) and maternal diet-induced obesity (Samuelsson et al. 2008, Nelson et al. 2010, Morandi et al. 2012) have been shown to produce offspring with increased BW or increased adiposity. Our study supported these previous findings, as both ART and diet affected offspring BW. Maternal and offspring consumption of a HF diet resulted in offspring with higher BW than the LF controls, and this effect persisted and increased from weaning (22 days) until killing ( $55 \pm 0.5$ days). However, the effect of ART that we observed on increased BW in the offspring decreased over time after weaning. This is similar to findings from a previous study (Scott et al. 2010), where female mouse offspring conceived using IVF had increased BW at 3 weeks of age when compared with no ART controls, but not from 4 weeks of age until 8 weeks of age. Further, one retrospective ART study in humans showed increases in child adiposity rather than BW (Ceelen et al. 2007), while the other showed increases in adiposity and BW (Belva et al. 2012). However, the study by Belva et al. (2012) involved ICSI, which is a more invasive ART procedure compared with those used in our study. Future studies examining the effect of ART on offspring should look at adiposity in addition to BW and also the type of ART procedure used to further clarify this issue.

Table 2 Table of significant correlations between measurements in mouse offspring.

\begin{tabular}{|c|c|c|c|c|c|c|c|}
\hline & Mmp9 & Timp1 & $C y b b$ & 2-OH-Et & Et & SacBW & MAP \\
\hline \multirow{3}{*}{ Mmp2 } & 0.717 & 0.742 & 0.374 & -0.364 & -0.280 & 0.317 & 0.225 \\
\hline & $<0.001$ & $<0.001$ & 0.006 & 0.008 & 0.045 & 0.021 & 0.112 \\
\hline & 53 & 53 & 53 & 52 & 52 & 53 & 51 \\
\hline \multirow[t]{3}{*}{ Mmp9 } & & 0.634 & 0.549 & -0.387 & -0.363 & 0.259 & 0.111 \\
\hline & & $<0.001$ & $<0.001$ & 0.005 & 0.008 & 0.061 & 0.439 \\
\hline & & 53 & 53 & 52 & 52 & 53 & 51 \\
\hline \multirow[t]{3}{*}{ Timp1 } & & & 0.479 & -0.420 & -0.293 & 0.178 & 0.157 \\
\hline & & & $<0.001$ & 0.002 & 0.035 & 0.203 & 0.274 \\
\hline & & & 53 & 52 & 52 & 53 & 51 \\
\hline \multirow[t]{3}{*}{$C y b b$} & & & & -0.338 & -0.258 & -0.007 & 0.223 \\
\hline & & & & 0.014 & 0.065 & 0.954 & 0.116 \\
\hline & & & & 52 & 52 & 53 & 51 \\
\hline \multirow[t]{3}{*}{ 2-OH-Et } & & & & & 0.848 & 0.009 & -0.264 \\
\hline & & & & & $<0.001$ & 0.939 & 0.04 \\
\hline & & & & & 67 & 67 & 61 \\
\hline \multirow[t]{3}{*}{ Et } & & & & & & 0.095 & -0.136 \\
\hline & & & & & & 0.444 & 0.294 \\
\hline & & & & & & 67 & 61 \\
\hline \multirow[t]{3}{*}{ SacBW } & & & & & & & 0.295 \\
\hline & & & & & & & 0.02 \\
\hline & & & & & & & 62 \\
\hline
\end{tabular}

The logarithms of the $\Delta C_{\mathrm{T}}$ for matrix metalloproteinase 2 (Mmp2) and Mmp9, tissue inhibitor of matrix metalloproteinase 1 (Timp1), and NADPH oxidase 2 (Nox2 (Cybb)) expression in thoracic aorta, extracellular 2-hydroxyethidium (2-OH-Et), and ethidium (Et) in mesenteric arterioles, body weight at killing (SacBW), and mean arterial pressure (MAP) were compared using correlational analysis. The values in each cell from top to bottom represent the Pearson's correlation coefficient, $P$ value, and number of measurements respectively. Boldface, significance at $P<0.05 ; \Delta C_{\mathrm{T}}$, difference in cycle threshold. 
Maternal and offspring diet had a greater effect on BW in the male offspring compared with females. Males from the HF group weighed significantly more when compared with the LF males than the HF females did when compared with LF females. This finding is supported by previous research that exhibited pronounced adverse metabolic outcomes in males born to an obese mother (Torrens et al. 2012, Magliano et al. 2013). To our knowledge, no studies have previously
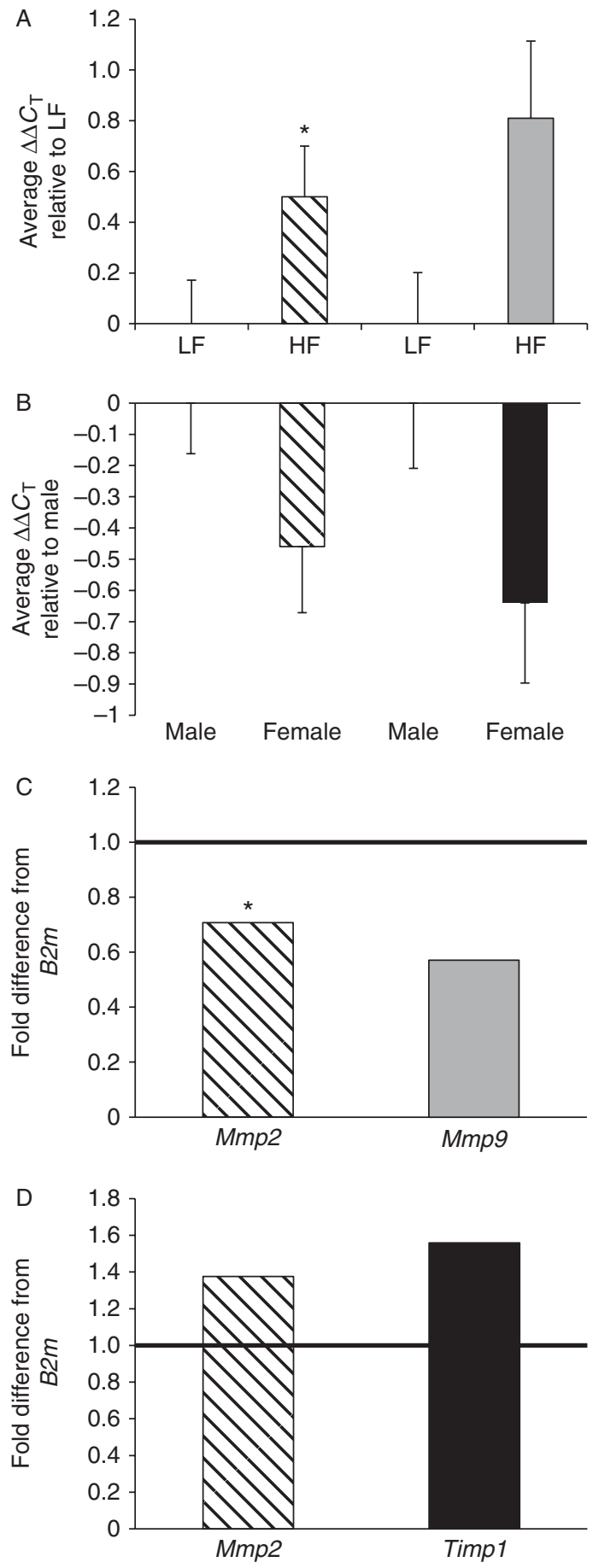

been performed to examine the effect of ART and a HF developmental environment together on juvenile offspring BW. Our study did not show a significant ART and diet interaction, suggesting that the adverse effects on offspring BW from these two environments are not amplified by the combination of ART and HF diet consumption, at least at the age examined.

It has been previously reported that increased BW can predispose an individual to adverse cardiovascular outcomes including hypertension and an increased risk for CVD (NIH 2012, Iguchi et al. 2013, Simoes-Silva et al. 2013). Data from our study support this previous research. First, males had increased BW when compared with females from weaning until killing, and this was accompanied by an increased MAP in males compared with females at killing. The difference in MAP between males and females is also supported by previous research showing that estrogens can have a protective effect on blood pressure response (reviewed in Xue et al. (2013)). Further, MAP had a positive overall correlation with BW at killing, showing that individuals who were heavier had higher MAP.

Previous research has also shown increased blood pressure in offspring born to mothers consuming a highfat diet (Samuelsson et al. 2008, Torrens et al. 2012). Results from our study support these findings, as HF diet consumption (both by the dam and the offspring) resulted in increased MAP in the offspring.

In humans, an association has previously been made between the use of ART and increased systolic and diastolic blood pressure in children (Ceelen et al. 2008, Sakka et al. 2010). These retrospective studies involved children at ages from 8 to 18 years old (Ceelen et al. 2008) and from 4 to 14 years old (Sakka et al. 2010), which we expect are comparable to the juvenile mice at 7 weeks of age that we studied. Further, an effect of ART on offspring blood pressure has also been observed in

Figure 3 Quantitative RT-PCR assessment of the expression of genes potentially involved in inward remodeling in offspring thoracic aortas. All gene expressions were normalized to the expression of $B 2 m\left(\Delta C_{\mathrm{T}}\right)$ and then averaged within the respective groups. (A) The relative difference in cycle thresholds $\left(\Delta \Delta C_{\mathrm{T}}\right)$ between the $\mathrm{HF}$ and $\mathrm{LF}$ treatment groups for Mmp2 and Mmp9. (B) The relative difference $\Delta \Delta C_{\mathrm{T}}$ between females and males for Mmp2 and Timp1. The error bars represent the S.E.M. The fold differences between treatment groups for each gene analyzed were then calculated. (C) Fold difference calculation of data presented in (A). (D) Fold difference calculation of data presented in (B). The solid black line across ' 1 ' demarcates ' $L F$ ' for the two bars in (C) (diet effect) and 'males' in (D) (sex effect). Mmp2, diagonal line bar; Mmp9, gray bar; Timp1, black bar. MMp2 - HF vs LF, females vs males; $n=24$ and 29, $n=24$ and 29 respectively. Mmp9-HF vs LF, $n=24$ and 29 respectively. Timp 1 - females vs males; $n=24$ and 29 respectively. All differences are significant at $P<0.05$, except for the asterisk $(*)$, which represents a trend at $P<0.1$. LF, consumption of maintenance chow by mothers and offspring. HF, maternal and offspring consumption of a diet with $24 \%$ fat and $17.5 \%$ high-fructose corn syrup. $\Delta C_{\mathrm{T}}$, change in cycle threshold; $B 2 \mathrm{~m}, \beta-2$ microglobulin. 

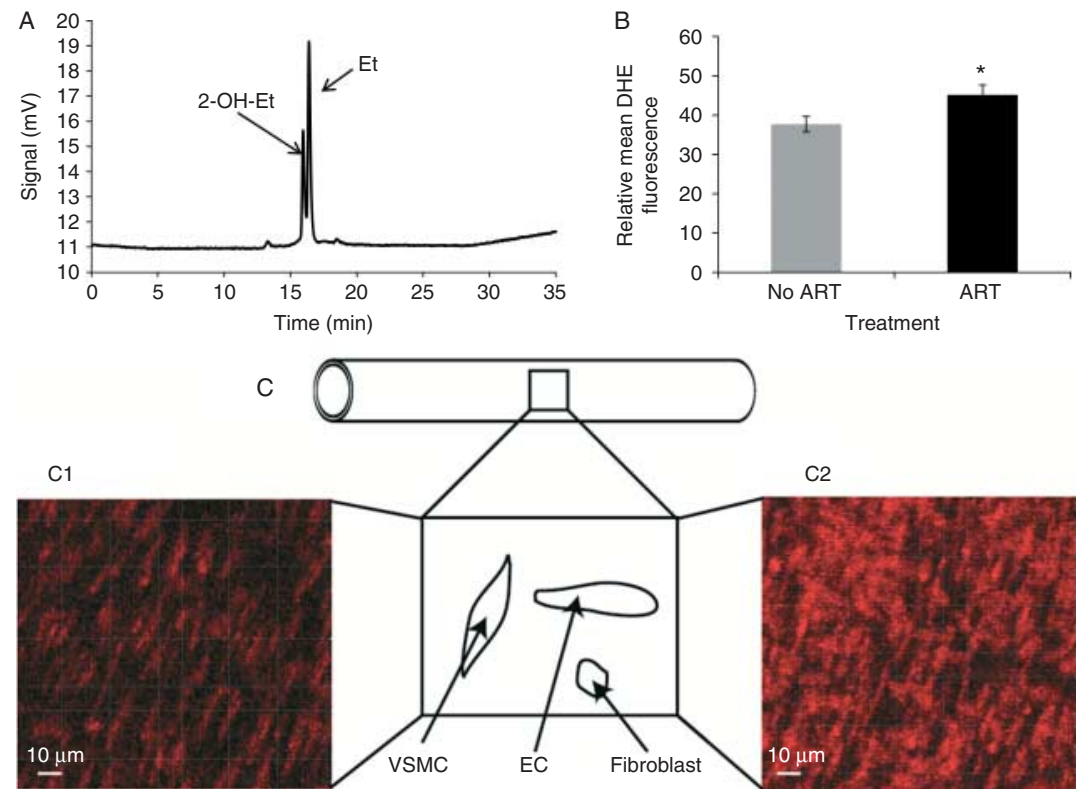

Figure 4 Detection of extracellular and intracellular ROS in mesenteric resistance arteries of offspring. (A) Two fluorescent byproducts of DHE were detected by HPLC in offspring ( $55 \pm 0.5$ days) mesenteric resistance arteries. Resistance arteries were incubated with $50 \mu \mathrm{M} D H E$ for $1 \mathrm{~h}$. 2-Hydroxyethidium (2-OH-Et; specific byproduct of superoxide and DHE) eluted at $16.19 \pm 0.03$ min and the ethidium (Et; less specific byproduct) eluted at $16.61 \pm 0.03 \mathrm{~min}$. Areas under each curve were determined using the Empower program (Waters, Build \#1154) and were normalized to the concentration of protein in each vessel before comparisons between treatments. Protein amounts were with a Micro BCA Protein Assay Kit.

(B) Determination of levels of intracellular ROS in offspring mesenteric resistance arteries using confocal microscopy for relative DHE fluorescence. Intracellular DHE fluorescence (red) was measured by confocal microscopy. Gain was set at $800 \mathrm{~V}$. Data represent the group average \pm s.E.M. of DHE fluorescence over the average of two areas of the mesenteric resistance arteries for offspring conceived naturally (no ART; gray, $n=32$ ) or with the use of ART (ART; black, $n=31$ ). (C) Shown is a diagrammatic representation of a resistance artery, indicating that a portion of the middle section of the vessel was flattened and the vascular wall imaged using confocal microscopy to detect DHE-dependent fluorescence. Within the wall nuclei of different cells (i.e. VSMC, vascular smooth muscle cells; EC, endothelial cells; and fibroblasts) bind to the dye and highlight its fluorescence intensity. Notice that the nuclei for different cells have specific morphologies and spatial orientations. The micrograph of a longitudinal section of a mesenteric resistance artery from a naturally conceived LF male is shown in (C1), and an ART-conceived LF male in (C2). Red fluorescence results from the oxidation of DHE. Fluorescence was quantified with the Imaris 7.6.1 Software. ART, assisted reproductive technologies; DHE, dihydroethidium; ROS, reactive oxygen species. ${ }^{*} P=0.056$.

mice (Watkins et al. 2007). Our study, however, did not show increased MAP due to ART. There are several differences between the Watkins et al.'s (2007) work and ours that could partially explain the difference in results. For example, in our study, we studied juvenile mice ( $\sim 7$ weeks of age) while they used older mice (i.e. 15 and 21 weeks of age). In addition, the strain of mice used varied between studies (NSA (CF1) females and B6D2F1/J males vs $(\mathrm{CBA} \times \mathrm{C} 57 / \mathrm{BL} 6) \mathrm{F} 1$ females and MF1 males for our and their studies respectively) and the embryo culture medium was different (Whitten's medium vs T6 medium, for our and their studies respectively). Finally, our measurement of MAP combines both systolic and diastolic pressure, while in the study by Watkins et al. (2007), only differences in systolic blood pressure were measured.

Interestingly, while offspring who were exposed to an obesogenic diet had increased MAP, they had lower expression of Mmp2 and Mmp9 when compared with offspring in the LF group. This is counterintuitive to previous studies that have suggested MMP2 and MMP9 to be involved in vascular remodeling associated with hypertension (Lehoux et al. 2004, Martínez-Lemus et al. 2011). However, in the study by Lehoux et al. (2004), MMP9 was shown to be involved in outward remodeling rather than inward remodeling (Lehoux et al. 2004), so increased MMP9 has been suggested to initially provide a compensatory response to increased pressure (Martínez-Lemus \& Galinanes 2011). Therefore, it is possible that the decreased Mmp9 expression found in the offspring with increased MAP is representative of a decreased ability of these offspring to compensate for their increased MAP. It should be noted that our interpretation of the results are based on measurements of signal for gene expression of the enzymes. Future experiments will determine whether protein expression and enzymatic activity align with our current findings.

Further, while males had increased MAP compared with females, they displayed decreased expression of Mmp2. However, they also displayed decreased expression of the inhibitor Timp1. Increased Timp1 expression has previously been shown to inhibit the activity of MMP2 and MMP9 (Zacchigna et al. 2004); therefore, it is possible that decreased Timp1 expression 
in the males is allowing for more MMP2 and MMP9 activity when compared with the females.

An ART effect was observed with levels of intracellular ROS in the offspring mesenteric resistance arteries. Superovulation, embryo culture, and embryo transfer were used in this experiment in order to simulate three of the procedures commonly used in human ART. In this initial study, we chose to use Whitten's medium to culture the embryos as this medium is known to be suboptimal for embryo development even though it is adequate to support development to full term (Ecker et al. 2004, Sommovilla et al. 2005). Future studies will determine whether similar effects are observed with various culture conditions. Offspring who were conceived using ART had increased levels of ROS in their mesenteric resistance arteries when compared with the offspring who were conceived naturally. While this increase was not accompanied by a significant change in MAP, this could predispose the offspring to greater vascular dysfunction and remodeling, as increased levels of ROS have been associated with reduced bioavailability of $\mathrm{NO}$ and vascular remodeling (Katakam et al. 2005, Martínez-Lemus et al. 2011). The increased levels of intracellular ROS in the ART group also occurred without a significant change in $C y b b$ expression. This could be an artifact of the different tissues used for ROS quantification and gene expression analysis. Alternatively, the increased ROS levels could be due to other producers of ROS (i.e. NOX1, NOX4, xanthine oxidase, and NO synthase (Cai et al. 2003, Bedard \& Krause 2007, Demarco et al. 2010)). Extracellular ROS levels were not significantly affected by any of the treatments.

We chose to study ROS levels in the resistance arteries, as the microvasculature is where most of the inward remodeling has been implicated in hypertension (Korsgaard et al. 1993). Owing to limited amounts of tissue from the microvasculature, we performed gene expression analysis in the aorta. Dysfunction in the aorta has also been implicated in adverse cardiovascular health in rodents, and studies have been performed examining the MMPs and TIMPs in the aorta (Allaire et al. 1998, Khan et al. 2012). While we acknowledge that the aorta (a large conduit vessel) and the resistance arteries (resistance vessels) are not the same, and we cannot make strong causative conclusions in our findings between the two tissues, we can still use our findings as possible markers of adverse cardiovascular health in the offspring. Previous studies have also used both large conduit vessels and small resistance vessels to examine cardiovascular health in rodents (Beyer et al. 2008, Davidson et al. 2010, Sakurada et al. 2010, Agbor et al. 2012).

In summary, our study has shown an effect of ART on offspring BW at weaning in a rodent model. We have also shown an effect of the use of ART on the level of ROS in mesenteric resistance arteries in the offspring. Maternal and offspring consumption of a HF diet resulted in an increased BW, MAP, and misregulated gene expression in the offspring aortas. We further found a relationship between elevated extracellular ROS from mesenteric resistance arteries and increased gene expression of $C y b b, M m p 2, M m p 9$, and Timp1 in the thoracic aorta. Knowledge is lacking on what effect the combination of ART and HF diet have on offspring BW and cardiovascular health, but our data suggest that the two developmental environments do not have an additive effect on BW, MAP, gene expression in thoracic aorta and ROS in mesenteric resistance arteries in juvenile mice. The experimental design used in this study does not allow us to differentiate whether the adverse cardiovascular outcomes observed were the result of exposure to an obesogenic diet prenatally or postnatally. Future research will examine this question. Further, as CVD in humans often does not present until adulthood (Jousilahti et al. 1999), follow-up studies will also determine whether an increased risk for adverse cardiovascular outcomes resulting from ART or obesogenic diet alone or in combination is evident later in life.

\section{Supplementary data}

This is linked to the online version of the paper at http://dx.doi. org/10.1530/REP-13-0354.

\section{Declaration of interest}

The authors declare that there is no conflict of interest that could be perceived as prejudicing the impartiality of the research reported.

\section{Funding}

A L Schenewerk is funded by a Miller Fellowship granted by MU Division of Animal Sciences. R M Rivera is funded by F21C. L A Martínez-Lemus is funded by grant R01 HL088105 from the National Heart, Lung and Blood Institute.

\section{Acknowledgements}

The authors would like to thank Matthew Sepúlveda from the Rivera laboratory for his valuable assistance with embryo transfer surgeries, and Guiling Zhao from the Martínez-Lemus laboratory for her help with isolation of the mesenteric resistance arteries.

\section{References}

Agbor LN, Walsh MT, Boberg JR \& Walker MK 2012 Elevated blood pressure in cytochrome P4501A1 knockout mice is associated with reduced vasodilation to omega-3 polyunsaturated fatty acids. Toxicology and Applied Pharmacology 264 351-360. (doi:10.1016/ j.taap.2012.09.007) 
Allaire E, Forough R, Clowes M, Starcher B \& Clowes AW 1998 Local overexpression of TIMP-1 prevents aortic aneurysm degeneration and rupture in a rat model. Journal of Clinical Investigation 102 1413-1420. (doi:10.1172/JCl2909)

Bailey-Downs LC, Tucsek Z, Toth P, Sosnowska D, Gautam T, Sonntag WE, Csiszar A \& Ungvari Z 2013 Aging exacerbates obesity-induced oxidative stress and inflammation in perivascular adipose tissue in mice: a paracrine mechanism contributing to vascular redox dysregulation and inflammation. Journals of Gerontology. Series A, Biological Sciences and Medical Sciences 68 780-792. (doi:10.1093/gerona/ gls238)

Bedard K \& Krause KH 2007 The NOX family of ROS-generating NADPH oxidases: physiology and pathophysiology. Physiological Reviews 87 245-313. (doi:10.1152/physrev.00044.2005)

Belva F, Painter R, Bonduelle M, Roelants M, Devroey P \& De Schepper J 2012 Are ICSI adolescents at risk for increased adiposity? Human Reproduction 27 257-264. (doi:10.1093/humrep/der375)

Beyer AM, Baumbach GL, Halabi CM, Modrick ML, Lynch CM, Gerhold TD, Ghoneim SM, de Lange WJ, Keen HL, Tsai YS et al. 2008 Interference with PPAR $\gamma$ signaling causes cerebral vascular dysfunction, hypertrophy, and remodeling. Hypertension 51 867-871. (doi:10.1161/ HYPERTENSIONAHA.107.103648)

Buettner GR 2008 DETAPAC (DTPA), Aqueous Stock Solution. Retrieved July 23, 2013 from http://www.healthcare.uiowa.edu/corefacilities/esr/ protocols/detapac/DETAPAC-Protocol.pdf

Cai H, Griendling KK \& Harrison DG 2003 The vascular NAD(P)H oxidases as therapeutic targets in cardiovascular diseases. Trends in Pharmacological Sciences 24 471-478. (doi:10.1016/S0165-6147(03)00233-5)

Ceelen M, van Weissenbruch MM, Roos JC, Vermeiden JP, van Leeuwen FE \& Delemarre-van de Waal HA 2007 Body composition in children and adolescents born after in vitro fertilization or spontaneous conception. Journal of Clinical Endocrinology and Metabolism 92 3417-3423. (doi:10.1210/jc.2006-2896)

Ceelen $M$, van Weissenbruch MM, Vermeiden JP, van Leeuwen FE \& Delemarre-van de Waal HA 2008 Cardiometabolic differences in children born after in vitro fertilization: follow-up study. Journal of Clinical Endocrinology and Metabolism 93 1682-1688. (doi:10.1210/ jc.2007-2432)

Ceelen $M$, van Weissenbruch MM, Prein J, Smit JJ, Vermeiden JP, Spreeuwenberg $M$, van Leeuwen FE \& Delemarre-van de Waal HA 2009 Growth during infancy and early childhood in relation to blood pressure and body fat measures at age 8-18 years of IVF children and spontaneously conceived controls born to subfertile parents. Human Reproduction 24 2788-2795. (doi:10.1093/humrep/dep273)

Chao HT, Lee SY, Lee HM, Liao TL, Wei YH \& Kao SH 2005 Repeated ovarian stimulations induce oxidative damage and mitochondrial DNA mutations in mouse ovaries. Annals of the New York Academy of Sciences 1042 148-156. (doi:10.1196/annals.1338.016)

Davidson EP, Coppey LJ, Calcutt NA, Oltman CL \& Yorek MA 2010 Dietinduced obesity in Sprague-Dawley rats causes microvascular and neural dysfunction. Diabetes/Metabolism Research and Reviews 26 306-318. (doi:10.1002/dmrr.1088)

Demarco VG, Whaley-Connell AT, Sowers JR, Habibi J \& Dellsperger KC 2010 Contribution of oxidative stress to pulmonary arterial hypertension. World Journal of Cardiology 2 316-324. (doi:10.4330/wjc.v2.i10.316)

Ecker DJ, Stein P, Xu Z, Williams CJ, Kopf GS, Bilker WB, Abel T \& Schultz RM 2004 Long-term effects of culture of preimplantation mouse embryos on behavior. PNAS 101 1595-1600. (doi:10.1073/pnas. 0306846101)

Eppig JJ, Wigglesworth K \& Pendola FL 2002 The mammalian oocyte orchestrates the rate of ovarian follicular development. PNAS 99 2890-2894. (doi:10.1073/pnas.052658699)

Franco JG, Fernandes TP, Rocha CP, Calvino C, Pazos-Moura CC, Lisboa PC, Moura EG \& Trevenzoli IH 2012 Maternal high-fat diet induces obesity and adrenal and thyroid dysfunction in male rat offspring at weaning. Journal of Physiology 590 5503-5518. (doi:10.1113/ jphysiol.2012.240655)

Gomez DE, Alonso DF, Yoshiji H \& Thorgeirsson UP 1997 Tissue inhibitors of metalloproteinases: structure, regulation and biological functions. European Journal of Cell Biology 74 111-122.
Hales CN \& Barker DJ 1992 Type 2 (non-insulin-dependent) diabetes mellitus: the thrifty phenotype hypothesis. Diabetologia 35 595-601. (doi:10.1007/BF00400248)

Hao L, Du M, Lopez-Campistrous A \& Fernandez-Patron C 2004 Agonistinduced activation of matrix metalloproteinase-7 promotes vasoconstriction through the epidermal growth factor-receptor pathway. Circulation Research 94 68-76. (doi:10.1161/01.RES.0000109413.57726.91)

Iguchi A, Yamakage H, Tochiya M, Muranaka K, Sasaki Y, Kono S, Shimatsu A \& Satoh-Asahara N 2013 Effects of weight reduction therapy on obstructive sleep apnea syndrome and arterial stiffness in patients with obesity and metabolic syndrome. Journal of Atherosclerosis and Thrombosis. (doi:10.5551/jat.17632)

Jousilahti P, Vartiainen E, Tuomilehto J \& Puska P 1999 Sex, age, cardiovascular risk factors, and coronary heart disease: a prospective follow-up study of 14786 middle-aged men and women in Finland. Circulation 99 1165-1172. (doi:10.1161/01.CIR.99.9.1165)

Kallen B, Finnstrom O, Lindam A, Nilsson E, Nygren KG \& Otterblad PO 2010 Congenital malformations in infants born after in vitro fertilization in Sweden. Birth Defects Research. Part A, Clinical and Molecular Teratology 88 137-143. (doi:10.1002/bdra.20645)

Katakam PV, Tulbert CD, Snipes JA, Erdos B, Miller AW \& Busija DW 2005 Impaired insulin-induced vasodilation in small coronary arteries of Zucker obese rats is mediated by reactive oxygen species. American Journal of Physiology. Heart and Circulatory Physiology 288 H854-H860. (doi:10.1152/ajpheart.00715.2004)

Kelsall CJ, Hoile SP, Irvine NA, Masoodi M, Torrens C, Lillycrop KA, Calder PC, Clough GF, Hanson MA \& Burdge GC 2012 Vascular dysfunction induced in offspring by maternal dietary fat involves altered arterial polyunsaturated fatty acid biosynthesis. PLOS ONE 7 e34492. (doi:10.1371/journal.pone.0034492)

Khan JA, Abdul Rahman MN, Mazari FA, Shahin Y, Smith G, Madden L, Fagan MJ, Greenman J, McCollum PT \& Chetter IC 2012 Intraluminal thrombus has a selective influence on matrix metalloproteinases and their inhibitors (tissue inhibitors of matrix metalloproteinases) in the wall of abdominal aortic aneurysms. Annals of Vascular Surgery 26 322-329. (doi:10.1016/j.avsg.2011.08.015)

Korsgaard N, Aalkjaer C, Heagerty AM, Izzard AS \& Mulvany MJ 1993 Histology of subcutaneous small arteries from patients with essential hypertension. Hypertension 22 523-526. (doi:10.1161/01.HYP. 22.4.523)

Lawlor DA, Najman JM, Sterne J, Williams GM, Ebrahim S \& Davey Smith G 2004 Associations of parental, birth, and early life characteristics with systolic blood pressure at 5 years of age: findings from the Mater-University study of pregnancy and its outcomes. Circulation 110 2417-2423. (doi:10.1161/01.CIR.0000145165.80130.B5)

Lehoux S, Lemarie CA, Esposito B, Lijnen HR \& Tedgui A 2004 Pressureinduced matrix metalloproteinase-9 contributes to early hypertensive remodeling. Circulation 109 1041-1047. (doi:10.1161/01.CIR.0000115 521.95662.7A)

Magliano DC, Bargut TC, de Carvalho SN, Aguila MB, Mandarim-deLacerda CA \& Souza-Mello V 2013 Peroxisome proliferator-activated receptors- $\alpha$ and $\gamma$ are targets to treat offspring from maternal diet-induced obesity in mice. PLoS ONE 8 e64258. (doi:10.1371/journal.pone. 0064258)

Martínez-Lemus LA \& Galinanes EL 2011 Matrix metalloproteinases and small artery remodeling. Drug Discovery Today. Disease Models 8 21-28. (doi:10.1016/j.ddmod.2011.06.002)

Martínez-Lemus LA, Zhao G, Galinanes EL \& Boone M 2011 Inward remodeling of resistance arteries requires reactive oxygen speciesdependent activation of matrix metalloproteinases. American Journal of Physiology. Heart and Circulatory Physiology $300 \mathrm{H} 2005-\mathrm{H} 2015$. (doi:10.1152/ajpheart.01066.2010)

Morandi A, Meyre D, Lobbens S, Kleinman K, Kaakinen M, RifasShiman SL, Vatin V, Gaget S, Pouta A, Hartikainen AL et al. 2012 Estimation of newborn risk for child or adolescent obesity: lessons from longitudinal birth cohorts. PLOS ONE 7 e49919. (doi:10.1371/journal. pone.0049919)

Nagy A, Vintersten $\mathbf{K}$ \& Behringer $\mathbf{R}$ Manipulating the Mouse Embryo: A laboratory manual. 2003 ed. Cold Spring Harbor: Cold Spring Harbor Laboratory Press; 2003. 
Negron-Perez VM, Echevarria FD, Huffman SR \& Rivera RM 2013 Determination of allelic expression of h19 in pre- and peri-implantation mouse embryos. Biology of Reproduction 88 97. (doi:10.1095/ biolreprod.112.105882)

Nelson SM, Matthews P \& Poston L 2010 Maternal metabolism and obesity: modifiable determinants of pregnancy outcome. Human Reproduction Update 16 255-275. (doi:10.1093/humupd/dmp050)

NIH 2012 Overweight and obesity statistics. Retrieved July 23, 2013 from http://win.niddk.nih.gov/publications/PDFs/stat904z.pdf

Olson CK, Keppler-Noreuil KM, Romitti PA, Budelier WT, Ryan G, Sparks AE \& Van Voorhis BJ 2005 In vitro fertilization is associated with an increase in major birth defects. Fertility and Sterility $\mathbf{8 4}$ 1308-1315. (doi:10.1016/j.fertnstert.2005.03.086)

Owusu-Ansah E, Yavari A \& Banerjee U 2008 A protocol for in vivo detection of reactive oxygen species. Protocol Exchange. (doi:10.1038/ nprot.2008.23)

Reefhuis J, Honein MA, Schieve LA, Correa A, Hobbs CA \& Rasmussen SA 2009 Assisted reproductive technology and major structural birth defects in the United States. Human Reproduction 24 360-366. (doi:10.1093/ humrep/den387)

Rinaudo P \& Schultz RM 2004 Effects of embryo culture on global pattern of gene expression in preimplantation mouse embryos. Reproduction 128 301-311. (doi:10.1530/rep.1.00297)

Robker RL 2008 Evidence that obesity alters the quality of oocytes and embryos. Pathophysiology 15 115-121. (doi:10.1016/j.pathophys.2008. 04.004)

Rodrigues SF, Tran ED, Fortes ZB \& Schmid-Schonbein GW 2010 Matrix metalloproteinases cleave the $\beta 2$-adrenergic receptor in spontaneously hypertensive rats. American Journal of Physiology. Heart and Circulatory Physiology 299 H25-H35. (doi:10.1152/ajpheart.00620.2009)

Sakka SD, Loutradis D, Kanaka-Gantenbein C, Margeli A, Papastamataki M, Papassotiriou I \& Chrousos GP 2010 Absence of insulin resistance and low-grade inflammation despite early metabolic syndrome manifestations in children born after in vitro fertilization. Fertility and Sterility 94 1693-1699. (doi:10.1016/j. fertnstert.2009.09.049)

Sakurada M, Yoshimoto T, Sekizawa N, Hirono Y, Suzuki N \& Hirata Y 2010 Vasculoprotective effect of cilostazol in aldosterone-induced hypertensive rats. Hypertension Research 33 229-235. (doi:10.1038/ hr.2009.211)

Samuelsson AM, Matthews PA, Argenton M, Christie MR, McConnell JM, Jansen EH, Piersma AH, Ozanne SE, Twinn DF, Remacle C et al. 2008 Diet-induced obesity in female mice leads to offspring hyperphagia, adiposity, hypertension, and insulin resistance: a novel murine model of developmental programming. Hypertension 51 383-392. (doi:10.1161/ HYPERTENSIONAHA.107.101477)

Samuelsson AM, Morris A, Igosheva N, Kirk SL, Pombo JM, Coen CW, Poston L \& Taylor PD 2010 Evidence for sympathetic origins of hypertension in juvenile offspring of obese rats. Hypertension $\mathbf{5 5}$ 76-82. (doi:10.1161/HYPERTENSIONAHA.109.139402)

Scherrer U, Rimoldi SF, Rexhaj E, Stuber T, Duplain H, Garcin S, de Marchi SF, Nicod P, Germond M, Allemann Y et al. 2012 Systemic and pulmonary vascular dysfunction in children conceived by assisted reproductive technologies. Circulation 125 1890-1896. (doi:10.1161/ CIRCULATIONAHA.111.071183)

Scott KA, Yamazaki Y, Yamamoto M, Lin Y, Melhorn SJ, Krause EG, Woods SC, Yanagimachi R, Sakai RR \& Tamashiro KL 2010 Glucose parameters are altered in mouse offspring produced by assisted reproductive technologies and somatic cell nuclear transfer. Biology of Reproduction 83 220-227. (doi:10.1095/biolreprod.109.082826)

Shertzer HG, Krishan M \& Genter MB 2013 Dietary whey protein stimulates mitochondrial activity and decreases oxidative stress in mouse female brain. Neuroscience Letters 548 159-164. (doi:10.1016/j.neulet. 2013.05.061)

Shimada I, Matsui K, lida R, Tsubota E \& Matsuki T 2009 Time course of housekeeping gene expression changes in diffuse alveolar damage induced by hyperoxia exposure in mice. Legal Medicine 11 (Suppl 1) S151-S154. (doi:10.1016/j.legalmed.2009.02.008)

Simoes-Silva L, Moreira-Rodrigues M, Quelhas-Santos J, FernandesCerqueira C, Pestana M, Soares-Silva I \& Sampaio-Maia B 2013
Intestinal and renal guanylin peptides system in hypertensive obese mice. Experimental Biology and Medicine 238 90-97. (doi:10.1258/ ebm.2012.012232)

Siwik DA, Pagano PJ \& Colucci WS 2001 Oxidative stress regulates collagen synthesis and matrix metalloproteinase activity in cardiac fibroblasts. American Journal of Physiology. Cell Physiology 280 C53-C60.

Sommovilla J, Bilker WB, Abel T \& Schultz RM 2005 Embryo culture does not affect the longevity of offspring in mice. Reproduction 130 599-601. (doi:10.1530/rep.1.00872)

Torrens C, Ethirajan P, Bruce KD, Cagampang FR, Siow RC, Hanson MA, Byrne CD, Mann GE \& Clough GF 2012 Interaction between maternal and offspring diet to impair vascular function and oxidative balance in high fat fed male mice. PLOS ONE 7 e50671. (doi:10.1371/journal.pone. 0050671)

Wang X, Chow FL, Oka T, Hao L, Lopez-Campistrous A, Kelly S, Cooper S, Odenbach J, Finegan BA, Schulz R et al. 2009 Matrix metalloproteinase-7 and ADAM-12 (a disintegrin and metalloproteinase-12) define a signaling axis in agonist-induced hypertension and cardiac hypertrophy. Circulation 119 2480-2489. (doi:10.1161/CIRCULATIONAHA.108. 835488)

Watkins AJ, Platt D, Papenbrock T, Wilkins A, Eckert JJ, Kwong WY, Osmond C, Hanson M \& Fleming TP 2007 Mouse embryo culture induces changes in postnatal phenotype including raised systolic blood pressure. PNAS 104 5449-5454. (doi:10.1073/pnas.0610317104)

Wen SW, Leader A, White RR, Leveille MC, Wilkie V, Zhou J \& Walker MC 2010 A comprehensive assessment of outcomes in pregnancies conceived by in vitro fertilization/intracytoplasmic sperm injection. European Journal of Obstetrics, Gynecology, and Reproductive Biology 150 160-165. (doi:10.1016/j.ejogrb.2010.02.028)

WHO 2013a Obesity and Overweight Fact Sheet. Retrieved July 23, 2013 from http://www.who.int/mediacentre/factsheets/fs311/en/

WHO 2013b Cardiovascular diseases (CVDs). Retrieved July 23, 2013 from http://www.who.int/mediacentre/factsheets/fs317/en/

Wikstrand MH, Niklasson A, Stromland K \& Hellstrom A 2008 Abnormal vessel morphology in boys born after intracytoplasmic sperm injection. Acta Paediatrica 97 1512-1517. (doi:10.1111/j.16512227.2008.00959.x)

Wildman RP, Mackey RH, Bostom A, Thompson T \& Sutton-Tyrrell K 2003 Measures of obesity are associated with vascular stiffness in young and older adults. Hypertension 42 468-473. (doi:10.1161/01.HYP. 0000090360.78539.CD)

Xue B, Johnson AK \& Hay M 2013 Sex differences in angiotensin II- and aldosterone-induced hypertension: the central protective effects of estrogen. American Journal of Physiology. Regulatory, Integrative and Comparative Physiology 305 R459-R463. (doi:10.1152/ajpregu.00222. 2013)

Yang Y, Estrada EY, Thompson JF, Liu W \& Rosenberg GA 2007 Matrix metalloproteinase-mediated disruption of tight junction proteins in cerebral vessels is reversed by synthetic matrix metalloproteinase inhibitor in focal ischemia in rat. Journal of Cerebral Blood Flow and Metabolism 27 697-709. (doi:10.1038/sj.jcbfm.9600375)

Zacchigna S, Zentilin L, Morini M, Dell'Eva R, Noonan DM, Albini A \& Giacca M 2004 AAV-mediated gene transfer of tissue inhibitor of metalloproteinases-1 inhibits vascular tumor growth and angiogenesis in vivo. Cancer Gene Therapy 11 73-80. (doi:10.1038/sj.cgt.7700657)

Zhang H, Wang ZW, Wu HB, Li Z, Li LC, Hu XP, Ren ZL, Li BJ \& Hu ZP 2013 Transforming growth factor- $\beta 1$ induces matrix metalloproteinase- 9 expression in rat vascular smooth muscle cells via ROS-dependent ERK-NF-kappaB pathways. Molecular and Cellular Biochemistry 375 11-21. (doi:10.1007/s11010-012-1512-7)

Received 2 August 2013

First decision 5 September 2013

Revised manuscript received 24 October 2013

Accepted 25 October 2013 